\title{
Digital Humanities for Higher Education
}

\section{Synonyms}

Humanities computing; Digital resources for the humanities; Humanities informatics

\section{Definition}

Digital Humanities (DH) covers a set of disciplines that cooperate in order to study, edit, teach and disseminate social and cultural heritage and dynamics thanks to digital tools. The most inclusive definition of the term "humanities" reflects both the human and social sciences (including media studies), and the corpuses and heritage they work on. The term "digital" refers to all the methods and techniques used to transform any object (text, sound, image, video or artefact) into digital data, the algorithms used to process these data (analysis, curation, conservation and edition) and the techniques used to render the results on a variety of media (visualisation, 3D printing, acoustic immersion, electronic art, etc.). DH is an interdisciplinary field bringing together a community of scholars and practitioners (archivists, librarians, etc.). However, the definition and limits of DH are subject to lively debates, especially with respect to who is in and who is out. The most restrictive definition of DH refers to a community of people who like to make things (code, applications, prototypes, digital resources, etc.), including in a class room, rather than devote their time to studying, reading and writing. In this sense, DH differs from the research and teaching associated with the traditional humanities.

\section{History}

The crossroads where computer science met with the humanities dates back to the 1940's with Lexical Text Analysis, Text Encoding, Machine Translation and Quantitative Sociology. In 2004, Schreibman et al. introduced the term Digital Humanities in order to capture the full range of new digital media (the web, social networks, video games, etc.) and create what people call today "the big tent" (the idea of bringing together researchers from various disciplines and viewpoints; this big tent approach is opposed to scientific specialisation and cohesiveness). Since then, many research and teaching centres have been created. In northern countries, these were initially attached to English departments. It was said that "Digital Humanities will save the Humanities" because it would attract new students (digital natives) and publics, reconcile the two cultures (science and humanities) and engage new teaching.

Indeed, DH programmes involve much group work and assessment as part of projects. DH encourages edupunk, i.e. a "do-it-yourself" ethos involving self and co-learning and a rebellious attitude to mainstream practices as well as action in favour of open access to culture, learning, data, scientific results and tools. Today, DH is backed on a growing number of campuses by computer science departments, digital infrastructures, and big interdisciplinary and international research projects. This has also led to criticism. It is said that technology will take over from the humanities scholars, that the DH community is predominantly made up of white scholars from a few English-speaking countries, that DH cannot lead to good scientific results in human science, that DH has rarely stopped to reflect on the tools it is creating, that the ethos of collaboration is uncritical and neglects political questions relating to access, equity, ethnicity, gender and language, and, finally, that the promise of DH is false: DH will not save the humanities after all.

However, DH has established itself (Schnapp et al, 2008; Schreibman et al, 2004) as a recognisable academic field with international conferences, events, books, journals and 
supporting institutions like the Office of Digital Humanities created by the US National Endowment for the Humanities.

Today, research and teaching programmes are visible and expanding across the world, and they are associated with cultural and historical transformation.

\section{Diversity in research and publication}

The DH community mainly comprises scholars from the USA, Canada and the UK. DH conferences, lists, associations, academic journals, and Twitter accounts are dominated by Anglo-American scholars. DH conference organisers and reviewers are also predominantly from these countries and hold leadership positions. English is apparently the main language for DH publications whereas research reflects different types of cultural heritage. Research projects, scientific results, teaching and publications in other countries have been largely invisible owing to the Anglo-American predominance.

However, since 2010, scholars from other European countries (e.g. France, Germany and Spain), Latin America (a region that is very much involved in the DH community), the Arab world, Africa, Australia, and Japan have been gaining visibility. In fact, there are DH practitioners in these regions of the world but they do not necessarily publish their results in English. The Italian Informatica Umanistica (Fiormonte, 2012) has a long tradition but this has been largely ignored by the Anglo-American hegemony. Some scholars (Clavert, 2013) acknowledge this predominance but note that it is not representative of the very active French or Spanish-speaking DH. Today, geographic and linguistic diversity genuinely exists in the DH field (Dariah, 2016; Galina Russell, 2014). Although English is the predominant language, this is because many scholars, who are not native English speakers, use it as a second language. Its use in the field as a first language is in fact marginal. Hence, the DH community working outside Anglo-American institutions is underrepresented.

Since 2013, the DH community has expressed a concern to broaden participation. Through different conferences and associations, scholars are seeking ways to become more inclusive of underrepresented countries and linguistic backgrounds.

\section{Teaching programmes}

Since 2000, many DH departments with graduate and postgraduate courses have been created. Initially, only a dozen or so came under the heading of DH. After a few years, the number of specialist courses, summer schools, Masters and Doctorates started to grow in the USA, Canada, Europe, but also in Latin America and Asia (e.g. the DH and Cultural Informatics programme at Jadavpur University, India (http://sctrdhci.wordpress.com/)). DH teaching programmes are developing, especially through modules offered in a variety of social sciences and humanities (SSH) departments. Most of these courses have only existed for a few years and do not cover all SSH disciplines. In some countries like France, the DH label is still rarely adopted. In the UK, the USA, Italy and Spain, scholars in philology, linguistics, literature and history were the first to develop DH. However, in French-speaking countries, major DH initiatives and programmes were undertaken with social scientists (e.g. the Lausanne University Master's degree in DH focusing on the development of computing skills for SSH and reflexive thinking on digital tools (https://www.unil.ch/lettres/fr/home/menuinst/master-et-specialisation/master-enhumanites-numeriques.html). In a growing number of cases, the initiative to set up programmes is being taken by computer scientists, data scientists or engineers. This is the case of the EPFL (Lausanne) Master's of Science in DH (http://master.epfl.ch/digitalhumanities), which covers data acquisition and analysis, 
audio and image processing, machine learning, pattern recognition, and data visualisation, with a focus on cultural, historical, and social media corpora. Sometimes the teaching programmes also cover art and design as in the case of the pan-Irish Digital Arts and Humanities (DAH) PhD program (http://dahphd.ie).

Anglo-American departments can usually put together interdisciplinary courses and programmes with no difficulty. The flexibility of the American Higher Education system has allowed courses in computer science for the humanities since the early 1970s. Sometimes, in order to reduce the cost of this training, they have linked teaching, research and consultancy services as in the King's College DH Department (http://www.kcl.ac.uk/artshums/depts/ddh/study/pgt/madh/index.aspx). In other countries, setting up interdisciplinary or inter-department courses can be more difficult although many have succeeded: the MA in DH at the University College of London (UCL), the MA in digital technology applied to history at the French École nationale de Chartes, the programme in informatics for SSH at Cologne University, the MA in Literatura en la Era Digital at the University of Barcelona, and the programmes offered by the Humanities Advanced Technology and Information Institute at the University of Glasgow.

At the European level, a number of networks bring together universities involved in teaching DH: the MA in European Heritage, Digital Media and the Information Society (Euromachs), the European Digital Scholarly Edition Initial Training Network (DiXiT), and DARIAH TEACH where open-source and multilingual teaching materials are developed.

\section{Teaching focus}

The prominent aspect of DH teaching is learning to use information technology for the digitisation of cultural heritage and its analysis. Since the 1990's in Italy, the university reform has made the teaching of information technology compulsory in all humanities disciplines. This has contributed to the development of the Italian DH. Sometimes, the teaching leads humanists to become technologists, designing tools to serve their own goals.

Usually, very few SSH students are attracted to computer science when they start their undergraduate programme. However, when they discover the relevance of computing to their discipline, some become interested in $\mathrm{DH}$ and either need to learn the basics of computing, even as late as when they undertake a $\mathrm{PhD}$, or want to become technically competent in their first years at university (Spiro, 2011).

Generally, advanced students also like to learn from one other, exchanging their knowhow about digital tools and their relevance to their discipline.

The pioneering and rebellious style of DH, and its "do-it-yourself" ethos, has led to colearning activities such as The Humanities and Technology Camp (THATCamp). Such camps are self-generated meetings bringing together technologists and SSH scholars but also librarians and archivists and cultural institution staff. Together, they learn how to integrate digital technology into their research, teaching or cultural activities. They organise a variety of sessions: talk sessions to discuss topics such as online publishing, open access, games, academic blogging, etc.; teach sessions during which participants with different levels of expertise teach each other a specific skill or how to use a digital tool or digital research methods, and engage in hands-on learning activities or share experience about specific know-how; make sessions are hands-on collaborative working sessions where participants actually produce something such as a piece of software, a preliminary analysis of a dataset, a best practices document; and, finally, demo or play 
sessions during which participants collaboratively explore new tools, resources or prototypes.

DH programmes are characterised by this style of learning, which stimulates collaborative projects, linking theory and practice and mixing humanities, social science, computing and art and design, and allowing the participants to engage with social media.

Many DH departments collaborate with public sector partners such as museums, archives, libraries and creative institutions. They work on their problems, resources and data and design solutions for the visualisation and circulation of results. In AngloAmerican countries, library and information sciences play an active role in the development of important digital platforms. Thus, DH has many driving forces. Humanities departments appear to be generally reluctant when it comes to setting up partnerships with the private sector, creative industry and businesses, and yet big firms, like Google, have largely benefited from SSH research results (e.g. computational linguistics), developing resources and applications for the humanities and cultural heritage, and employing DH graduates.

DH is producing a new HE community by bringing together scientists and practitioners from different fields. The boundaries of this new field are still under debate. Referring to a community of people who like to make things rather than studying, reading and writing, creates tension for traditional humanities research and teaching. The future of DH remains an open question.

\section{Cross-References}

Distance teaching universities, e-Learning

\section{References}

Clavert, Frédérc. 2013. The DH multicultural revolution did not happen yet.http://www.clavert.net/the-digital-humanities-multicultural-revolution-did-nothappen-yet/. Accessed 29 January 2017.

Dariah. 2016. European survey on scholarly practices and digital needs in the arts and humanities. Dariah-EU. DiMPO. October 2016. https://doi.org/10.5281/zenodo.260101 Fiormonte, Domenico. 2012. Towards a Cultural Critique of the Digital Humanities. Historical Social Research 37 (3): 59-76.

Galina Russell, Isabel. 2014. Geographical and linguistic diversity in the Digital Humanities. Literary and Linguistic Computing 29 (3): 307-316.

Schnapp, Jeffrey, Todd Presner, Peter Lunenfeld, and Johanna Drucke. 2008. A digital humanities manifesto. http://manifesto.humanities.ucla.edu/2008/12/15/digitalhumanities-manifesto/. Accessed 29 January 2017.

Schreibman, Susan, Ray Siemens, and John Unsworth (ed.). 2004. A Companion to Digital Humanities, Oxford: Wiley-Blackwell. http://www.digitalhumanities.org/companion/

Spiro, Lisa. 2011. Knowing and Doing: Understanding the Digital Humanities Curriculum. NITLE Labs. https://digitalscholarship.files.wordpress.com/2011/06/spirodheducationpresentation 2011-4.pdf. Accessed 29 January 2017. 